\title{
Erratum to: On shear instability and propagation of surface gravity waves in sea straits
}

The Publishers

Società Italiana di Fisica and Springer-Verlag GmbH Germany, part of Springer Nature

Original article: Eur. Phys. J. Plus (2018) 133: 475, https://doi.org/10.1140/epjp/i2018-12275-7

Received: 26 November 2018 / Revised: 26 November 2018

Published online: 30 November 2018

(C) Società Italiana di Fisica / Springer-Verlag GmbH Germany, part of Springer Nature, 2018

Due to a technical problem, figs. 1 and 2 have been slightly trimmed in the final version. Find here the correct versions of figs. 1 and 2 .

The Publishers regret this mistake and apologize for any inconvenience caused.
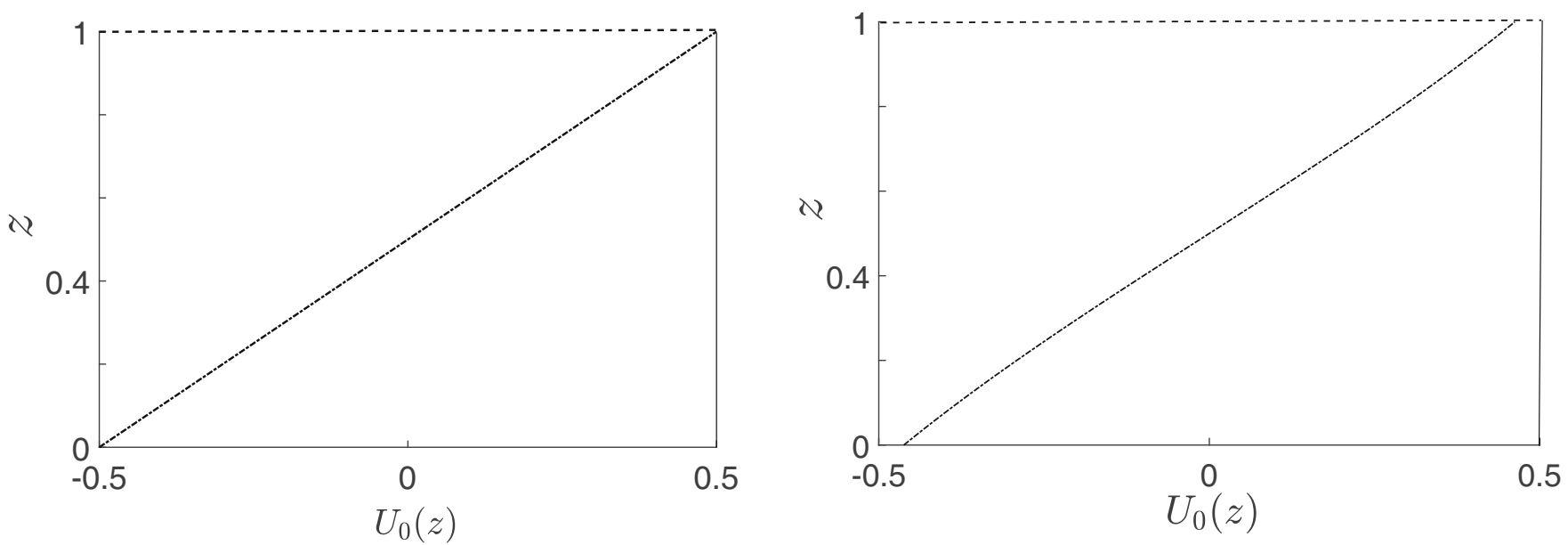

Fig. 1. Velocity profiles in examples 1 and 2 : (a) Velocity profile of $U_{0}(z)=z-1 / 2$; (b) velocity profile of $U_{0}(z)=\tanh (z-1 / 2)$.
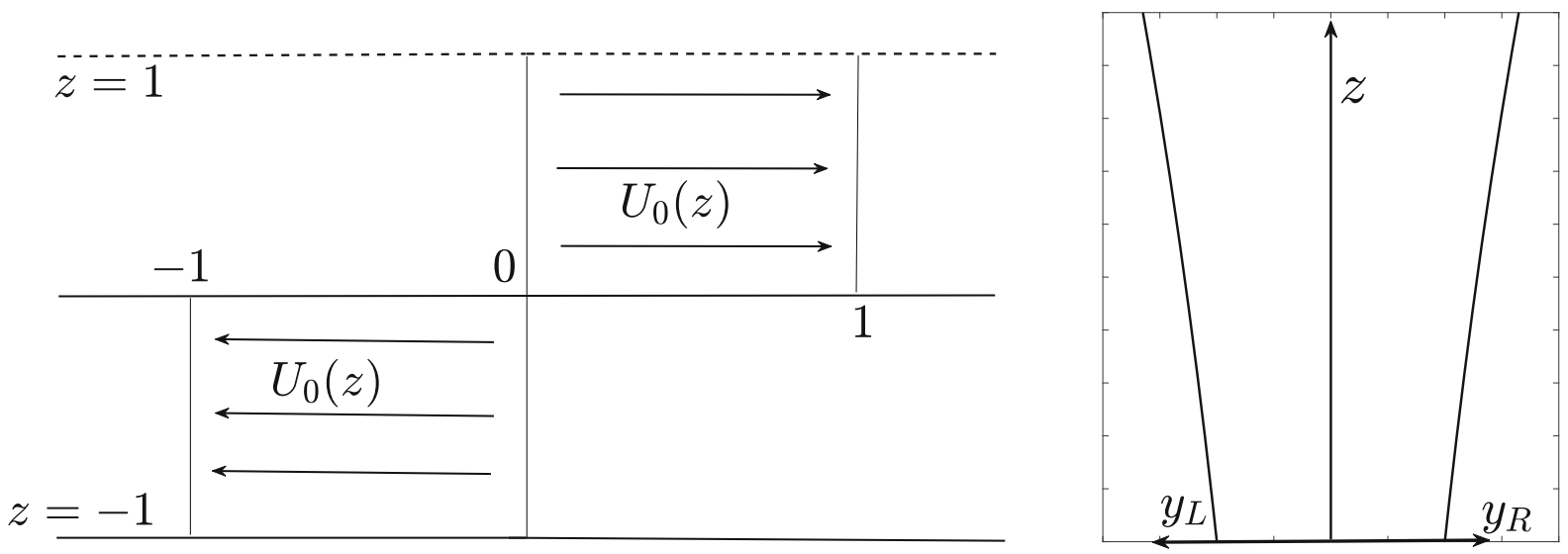

Fig. 2. Velocity profile and width function of the channel: (a) Bounded vortex sheet with a free upper surface; (b) topography. 